\title{
Review of Loss of Excitation Protection Setting and Coordination to the Generator Capacity Curve.
}

\author{
M.D. López, C.A. Platero, P. L. Mayor, R. Granizo
}

\section{INTRODUCTION}

The protection relays are essential not only for the reliability of the power system, but also for assuring the safe operation under faulty conditions. In generation power plants, protective systems are vital to guarantee the safety of the personnel and to minimize the possible damage on the power components and equipment during any type of events [1].

The correct setting and coordination of the protection relays is also extremely important, since inaccurate setting might lead either to the disconnection of the generation unit from the power system in some events that do not represent a real danger, or disabling a trip when it is necessary. This fact is not only an economical matter but also a stability issue in power systems, above all in power system with a high renewable energies penetration. The settings of the protections are selected according to the recommendations of the main standards and manufacturer guides as [2].

The loss of excitation in synchronous machines is a very active research topic, some new techniques, as the calculation of the internal voltage [3], adaptive Mho relays [4], setting-free relay [5] and other new developments [6]-[8].

There are several ways to protect the machines against loss of excitation, nowadays mainly the minimum reactance relay is used [9].

Traditionally the generators produce the reactive power demand for the loads. In the case of factories, the power factor is close to one, and the industrial generators produce the reactive power demanded by the factories.

However, with the liberalization of the electrical markets, in some cases the absorption of reactive power to help in the voltage regulation is subsidized, for example in the Spain.
Therefore, it is important to operate safely the generator in the sub-excited area. There have been several unwanted trip on some generators when operating in this conditions by the loss of excitation relay (40). After the analysis of several unwanted trips, we found several reasons, as:

-Wrong wiring of the protection relays.

-Wrong settings of the automatic voltage regulator.

-Wrong settings of the loss of excitation protection.

The normal practice for setting the loss of excitation protection (40) is to follow the recommendations of the relays manufacturers as [2]. However, there are different recommendations, all of them based on the direct-axis synchronous reactance $\mathrm{X}_{\mathrm{d}}$ and sub-transient direct-axis synchronous reactance $\mathrm{X}_{\mathrm{d}}^{\prime}$.

In order to ensure the correct operation of this protection, it should be coordinated with the P-Q capacity curve of the synchronous machine. [10]

So that the area of operation of the relay is outside the allowed zone of operation of the synchronous machine. Another important issue, for the proper operation of the machine, is the setting of the automatic voltage regulator (AVR), in order to not operate the generator out of theirs limits.

This paper presents a review of different setting recommendation from several relay manufacturers and its representation into the $\mathrm{PQ}$ diagram together with the generator capacity curve. Additionally numerous simulations have been performed in order to check the setting's operation.

\section{MinIMUM REACTANCE LOSS-OF-EXCITATION PROTECTION OPERATION PRINCIPLE.}

The synchronous machines need a DC current in the field winding to operate correctly. If a lack of current in the field 
winding takes place, it could produce severe damages in the machine. In the first stage, the reactive power consumed by the machine would increase, as well as the stator current, whereas the terminal voltage decreases drastically. In case of low active power operation the machine will operates as asynchronous generator at a low level of slip.

In the second stage, the generator speed rises, since its electrical torque is not enough to compensate the turbine torque. If this situation continues, the over-speed in the generator can lead to very severe damages in the turbogenerator.

The loss-of-excitation protection is based on the calculation of the impedance at generator terminals. The generator voltage $U$ depends on the excitation current $I_{f}$ according to equations (1) and (2).

$$
|E|=k \cdot I_{f}
$$

$\underline{U}=\underline{E}-j \cdot X_{d} \cdot \underline{I} \quad=\underline{k} \cdot I_{f}-j \cdot X_{d} \cdot \underline{I}$

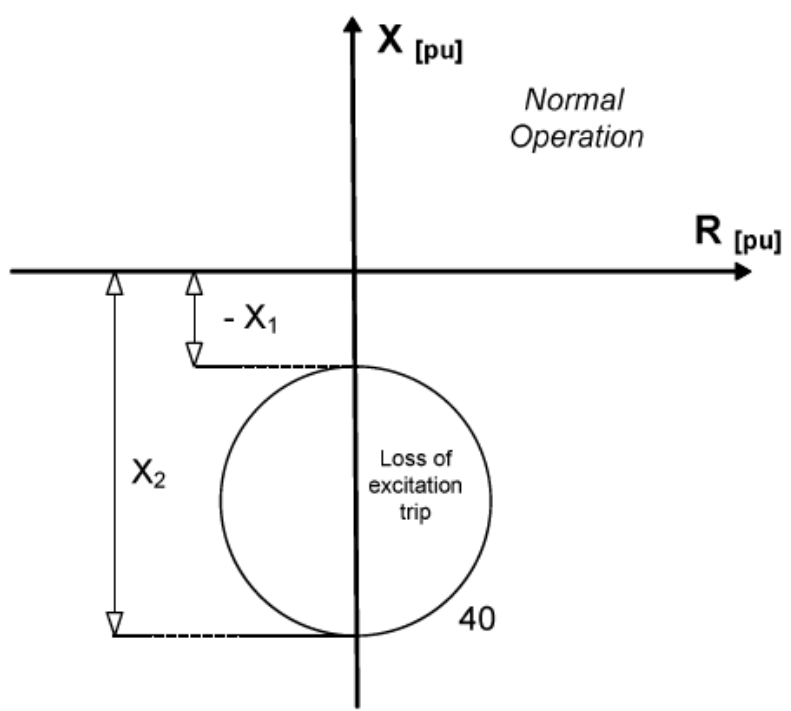

Fig. 1. Impedance characteristics $(\mathrm{R}-\mathrm{X})$ of a loss of excitation protection.

On the other hand, the impedance at generator terminals can be express as follow:

$\underline{\mathrm{Z}}=\underline{\mathrm{U}} / \underline{\mathrm{I}}=\underline{\mathrm{E}} / \underline{\mathrm{I}}-\mathrm{j} \cdot \mathrm{X}_{\mathrm{d}}=\underline{\mathrm{k} \cdot \mathrm{I}_{\mathrm{f}}} / \underline{\mathrm{I}}-\mathrm{j} \cdot \mathrm{X}_{\mathrm{d}}$

In case of loss of excitation, the voltage $E$ will be null and the impedance seen is inductive and negative, as show in the equation (4).

$I_{f}=0 \quad \rightarrow \quad Z=-j \cdot X_{d}$

The characteristic of the loss of excitation protection is presented in the Fig. 1. If the impedance seen in the generator terminals is inside the circle defined by $-X_{1}$ and $X_{2}$, the fault is detected.

\section{SYNCRHONOUS MACHINE CAPACITY CURVES AND THE COORDINATION (40)}

The synchronous machines capability is determinate by the maximum stator current, field current and the stability limit as shown in the Fig. 2 for a cylindrical rotor machine. It is remarkable that the practical stability limit corresponds to a load angle smaller than $90^{\circ}$.

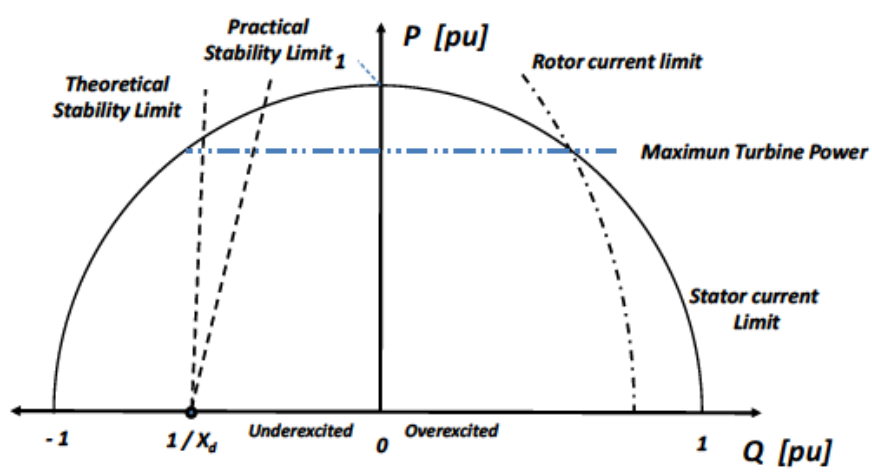

Fig. 2. Typical Cylindrical Rotor Synchronous generator capacity curve PQ

In case of salient pole synchronous machines the operation area is slightly different, as shown in Fig 3.

These curves determine the allowed operation zone of the machine.

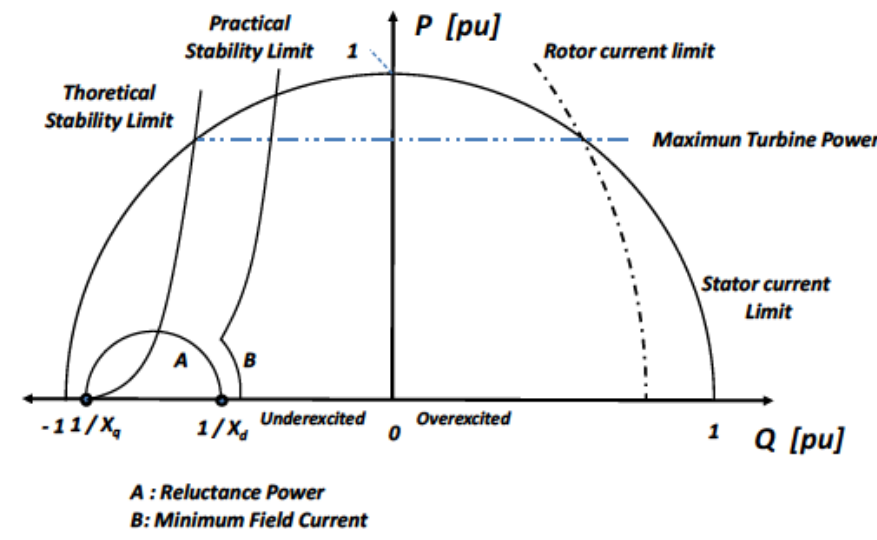

Fig. 3. Typical Salient Pole Synchronous generator capacity curve PQ.

On the other hand the loss of excitation protection characteristics is normally represented in the impedance plane $\mathrm{R}-\mathrm{X}$. In order to guaranty the operation of the machine in the

allowed operation zone, especially in the under-excited part, the setting of the loss of excitation protection should be coordinated with the generator capacity curve.

One possible way of coordination is to represent the setting of the protection into de P-Q plane instead of in the impedance 
plane R-X. For this purpose the following equations could be used.

$$
\begin{gathered}
\mathrm{Q}=\frac{\mathrm{X}^{*} \mathrm{~V}_{\mathrm{t}}^{2}}{\mathrm{R}^{2}+\mathrm{X}^{2}} \quad(I) \quad \mathrm{P}=\frac{\mathrm{R}^{*} \mathrm{~V}_{\mathrm{t}}^{2}}{\mathrm{R}^{2}+\mathrm{X}^{2}}(I I) \\
\mathrm{X}=\frac{\mathrm{Q}^{*} \mathrm{~V}_{\mathrm{t}}^{2}}{\mathrm{P}^{2}+\mathrm{Q}^{2}}(I I I) \quad \mathrm{R}=\frac{\mathrm{P}^{*} \mathrm{~V}_{\mathrm{t}}^{2}}{\mathrm{P}^{2}+\mathrm{Q}^{2}}(I V)
\end{gathered}
$$

In the Fig. 4 the setting of the loss of excitation protection is represented. The loss of excitation trip area should not overlap the generator allowed operation zone.

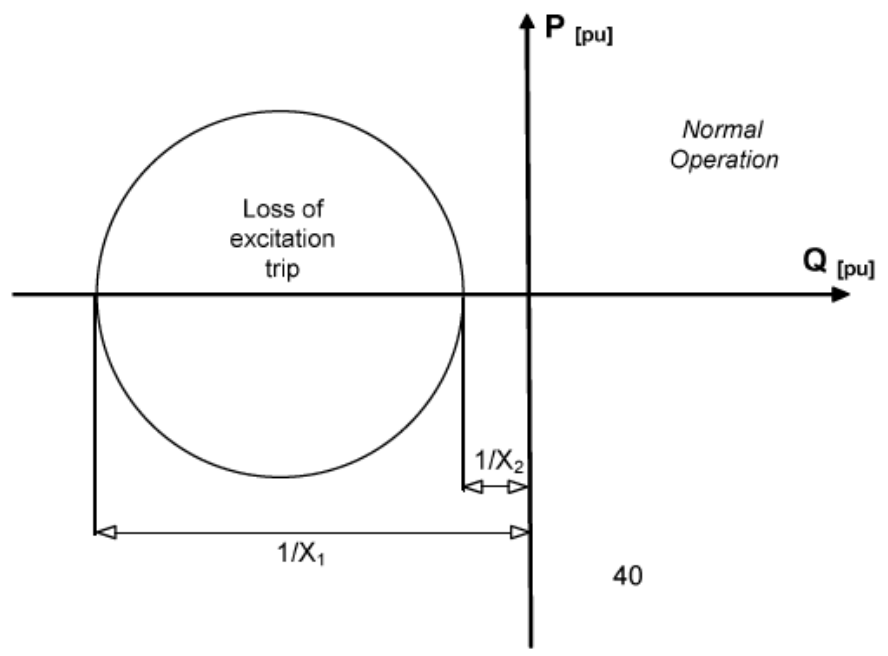

Fig. 4. Power characteristics $(\mathrm{PQ})$ of a loss of excitation protection.

\section{RECOMMENDATION SETTINGS}

The settings are expressed in different ways. In order to homogenise the setting, in this paper it is going to consider the reactance $-X_{1}$, which is the offset, and $X_{2}$ which is the minimum reactance; in other word the offset plus the diameter of the operation trip area.

After the study of numerous manufactures recommendations and scientific papers we have found the followings settings as shown in Table 1 .

It is significant that the vast majority of the recommendation employs a negative offset and all of them use - $\mathrm{X}_{d}^{\prime} / 2$. [11]. There are several manufacturers which setting recommendations is expressed as Offset $\left(-\mathrm{X}_{1}\right)$ and Diameter $\left(\mathrm{X}_{2}-\mathrm{X}_{1}\right)$. It is a very common recommendation that the diameter is the $X_{d}$, so the value of $X_{2}$ is $X_{d}+X_{d}^{\prime} / 2$.
TABLE I

LOSS OF EXCITATION SETTING RECOMMENDATIONS

\begin{tabular}{|l|c|c|}
\hline \multicolumn{1}{|c|}{ Settings } & $\mathrm{X}_{\mathrm{l}}[\mathrm{pu}]$ & $\mathrm{X}_{2}[\mathrm{pu}]$ \\
\hline 1 Salient pole & $-\mathrm{X}_{\mathrm{d}}{ }^{\prime} / 2$ & $0.8 \mathrm{X}_{\mathrm{d}}$ \\
\hline 1 Synchronous motor & $-\mathrm{X}_{\mathrm{d}}{ }^{\prime} / 2$ & $0.8 \mathrm{X}_{\mathrm{d}}$ \\
\hline 1 Cylindrical rotor & $-\mathrm{X}_{\mathrm{d}}{ }^{\prime} / 2$ & $\mathrm{X}_{\mathrm{d}}$ \\
\hline 2 Any type & $-\mathrm{X}_{\mathrm{d}}{ }^{\prime} / 2$ & $\mathrm{X}_{\mathrm{d}}$ \\
\hline 3 Any type & $-\mathrm{X}_{\mathrm{d}}{ }^{\prime} / 2$ & $(1.1-1.15) \mathrm{X}_{\mathrm{d}}$ \\
\hline 4 Any type & $-\mathrm{X}_{\mathrm{d}}{ }^{\prime} / 2$ & $\mathrm{X}_{\mathrm{d}}+\mathrm{X}_{\mathrm{d}}{ }^{\prime} / 2$ \\
\hline 5 Any type & $-\mathrm{X}_{\mathrm{d}}{ }^{\prime} / 2$ & $\mathrm{X}_{\mathrm{d}}+\mathrm{X}_{\mathrm{d}}{ }^{\prime} / 2$ \\
\hline 6 Any type & $-\mathrm{X}_{\mathrm{d}}{ }^{\prime} / 2$ & $\mathrm{X}_{\mathrm{d}}$ \\
\hline 7 Any type & $-\mathrm{X}_{\mathrm{d}}{ }^{\prime} / 2$ & $\mathrm{X}_{\mathrm{d}}+\mathrm{X}_{\mathrm{d}}{ }^{\prime} / 2$ \\
\hline
\end{tabular}

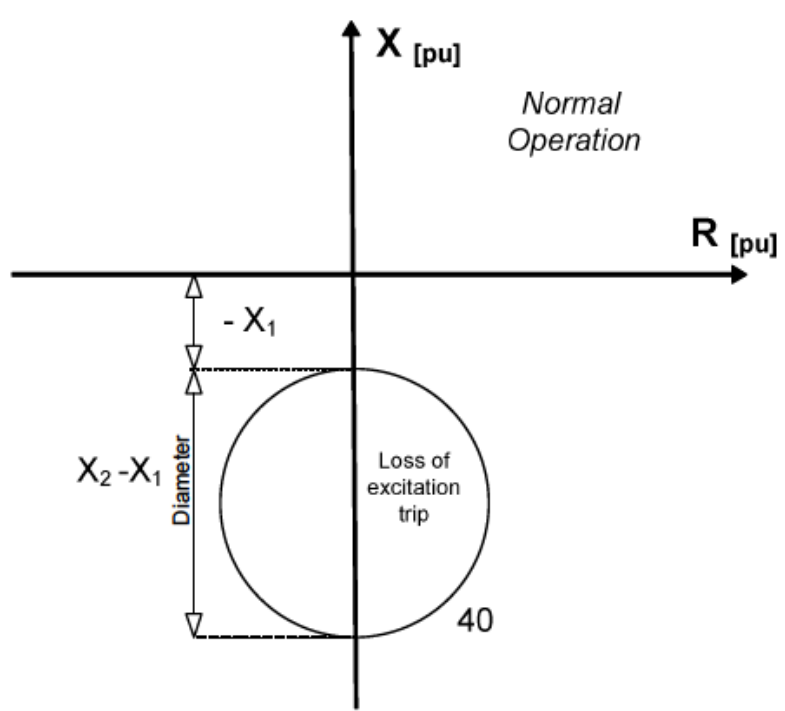

Fig. 5. Impedance characteristics (R-X) of a loss of excitation protection defined by the Offset $\left(-\mathrm{X}_{1}\right)$ and the diameter $\left(\mathrm{X}_{2}-\mathrm{X}_{1}\right)$

\section{SIMULATIONS}

The simulations correspond to a hydro power station connected to a non-infinite bus bar, which main data are listed in the Table II, III and IV. They have been performed with Matlab SimPowerSystems software.

Several events are considered to check the correct operation of the different settings of the loss of excitation protection, as loss of excitation at full load and short-circuit in the $220 \mathrm{kV}$ mains.

Firstly the different settings considered for the loss of excitation protection are represented in the Fig. 7 in the P-Q plane, with the generator limits. As it is clearly observed if the setting of $\mathrm{X}_{1}$ is larger than $\mathrm{X}_{\mathrm{d}}$ the protection area could overlap with the generator curve capacity. On the other hand is the setting of $\mathrm{X}_{1}$ is lower than $\mathrm{X}_{\mathrm{d}}$ the protected area could be far from the generator capacity curve. This considerations are valid 
for steady state, for transient, the computer model should be used.

TABLE II

SYNCHRONOUS MACHINE REACTANCES AND TIME CONSTANTS

\begin{tabular}{|l|r|c|}
\hline Rated apparent power & 50 & $\mathrm{MVA}$ \\
Rated Power Factor & 0.85 & \\
Rated voltage $( \pm 5,0 \%)$ & 11 & $\mathrm{kV}$ \\
Frequency & 50 & $\mathrm{~Hz}$ \\
Rated speed & 250 & $\mathrm{rpm}$ \\
Direct-axis synchronous reactance (unsat) $X_{d}$ & 1.190 & $\mathrm{pu}$ \\
Quadrature-axis synchronous reactance $X_{q}$ & 0.819 & $\mathrm{pu}$ \\
Direct-axis subtransient reactance (unsat) $X_{{ }_{d}}$ & 0.337 & $\mathrm{pu}$ \\
Direct-axis subtransient reactance (unsat) $X^{\prime \prime}{ }_{d}$ & 0.243 & $\mathrm{pu}$ \\
Quadrature-axis subtransient reactance $X^{\prime \prime}{ }{ }_{q}$ & 0.291 & $\mathrm{pu}$ \\
Transient open-circuit time constant $T^{\prime}{ }_{d o}$ & 7.430 & $\mathrm{~s}$ \\
Sub-transient open-circuit time constant $T^{\prime \prime}{ }_{d o}$ & 0.048 & $\mathrm{~s}$ \\
Direct-axis transient short-circuit time const $T^{\prime}{ }_{d}$ & 211 & $\mathrm{~ms}$ \\
Direct-axis subtransient short-circuit time const $T^{\prime \prime}{ }_{d}$ & 42 & $\mathrm{~ms}$ \\
\hline
\end{tabular}

TABLE III

GENERATION TRANSFORMER UNIT

\begin{tabular}{|l|r|r|}
\hline Rated power & 50 & MVA \\
Winding connection & YNd1 & \\
HV rated voltage & 220 & $\mathrm{kV}$ \\
LV rated voltage & 11 & $\mathrm{kV}$ \\
Short-circuit impedance & 10 & $\%$ \\
\hline
\end{tabular}

TABLE IV

POWER SYSTEM $220 \mathrm{KV}$

\begin{tabular}{|l|r|r|}
\hline Three phase short circuit & 2750 & MVA \\
X/R ratio & 10 & \\
\hline
\end{tabular}

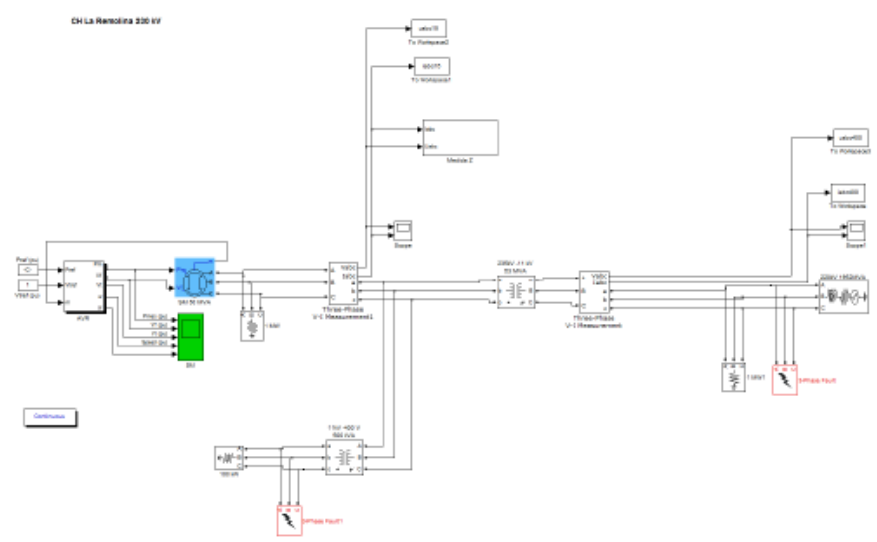

Fig. 6. Simplified power-plant simulation model.

The first simulations, corresponding to the loss of excitation, are performed setting to zero the excitation voltage of the field winding. The impedance at generator terminals are represented in the Fig. 8. It is represented as well the different setting of the loss of excitation protection, represented in the R$\mathrm{X}$ plane. It can be clearly observed than the impedance go in any of the circle corresponding to the different settings. For this failure, loss of excitation, any setting is suitable.

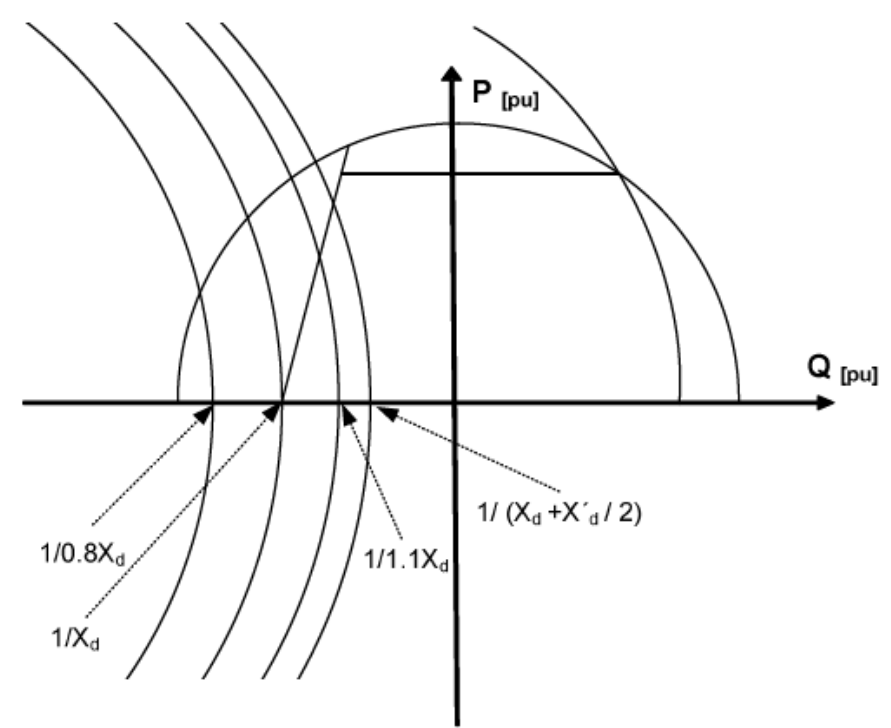

Fig. 7. Representation of the capacity curve of the generator and the diferent settings of the loss of excitation protection.

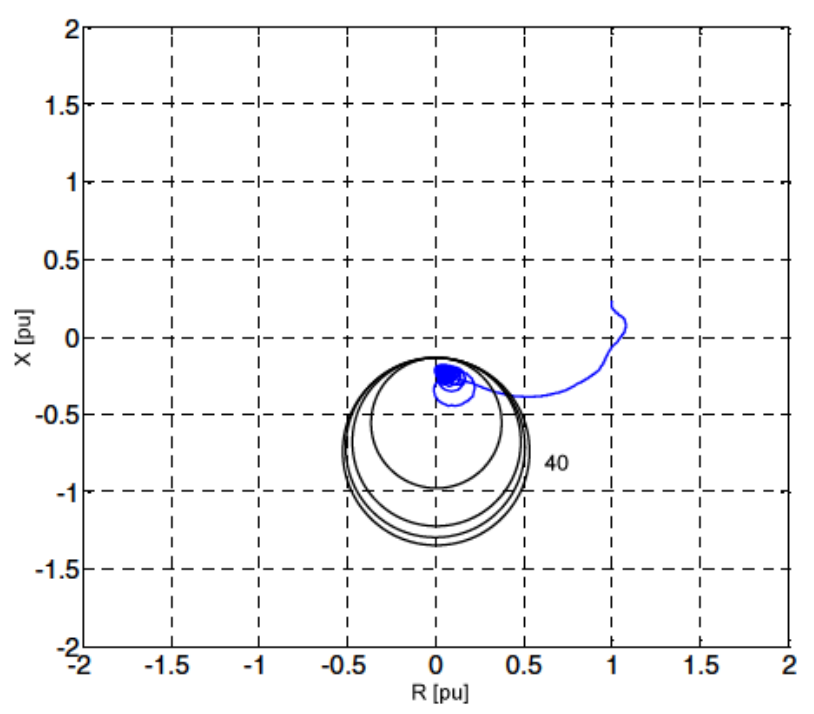

Fig. 8. Impedance at generator terminals simulation results of a loss of excitation for different loss of excitation protection settings.

In the Fig. 9 and 10 the generator currents and the generator load angle are represented respectively.

Thanks to several simulations of short-circuits in the 220 $\mathrm{kV}$ power system, the maximum fault clearance time has been evaluated. The maximum fault clearance time is $215 \mathrm{~ms}$. Short-circuits durations larger than $215 \mathrm{~ms}$ produce loss of stability. In the Fig. 11, 12 and 13 the impedance at generator terminal, the generator currents and the generator load angle are presented for a $215 \mathrm{~ms}$ three phases short-circuit in the 220 $\mathrm{kV}$ power system. (stable) 
In the case of a stable short-circuit the impedance at generator terminal does reach the protected area, but should be studied and coordinated to the loss of excitation tripping time.

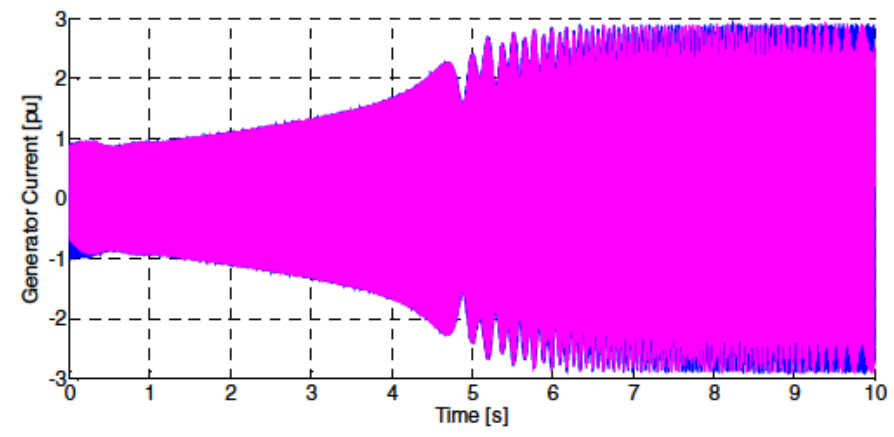

Fig. 9. Generator currents simulation results of a loss of excitation.

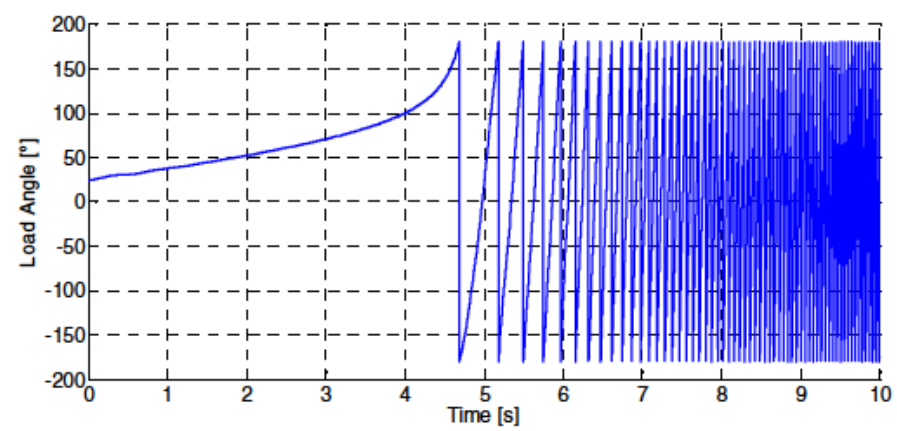

Fig. 10. Generator load angle simulation results of a loss of excitation.

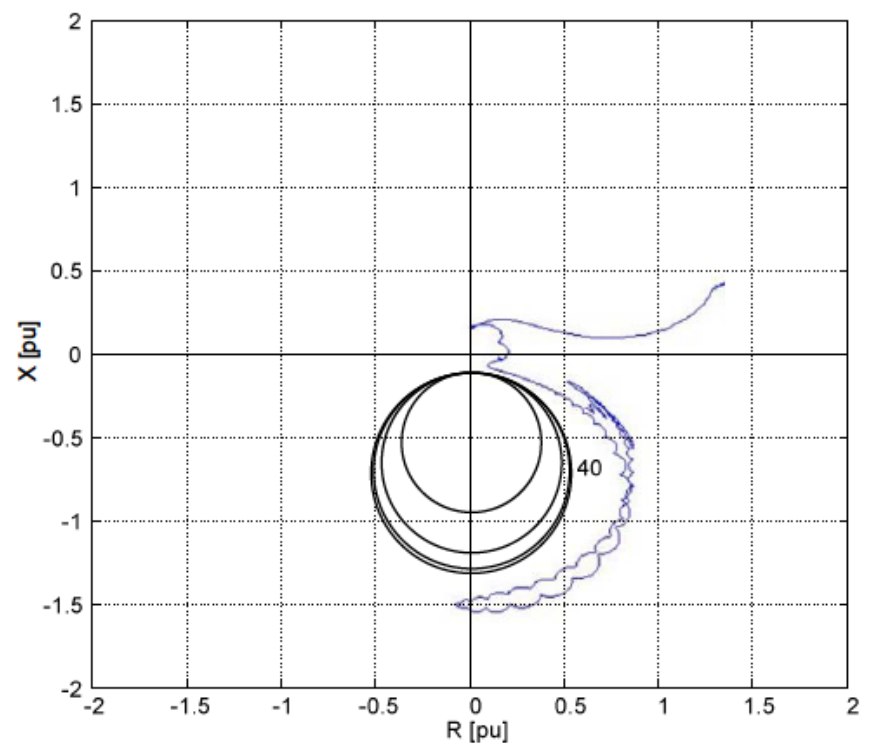

Fig. 11. Impedance at generator terminals simulation results of a short-circuit in $220 \mathrm{kV}$ of $215 \mathrm{~ms}$ for different loss of excitation protection settings

In the Fig. 14, 15 and 16 the impedance at generator terminal, the generator currents and the generator load angle are presented for a $220 \mathrm{~ms}$ three phases short-circuit in the 220 $\mathrm{kV}$ power system. (loss of stability).

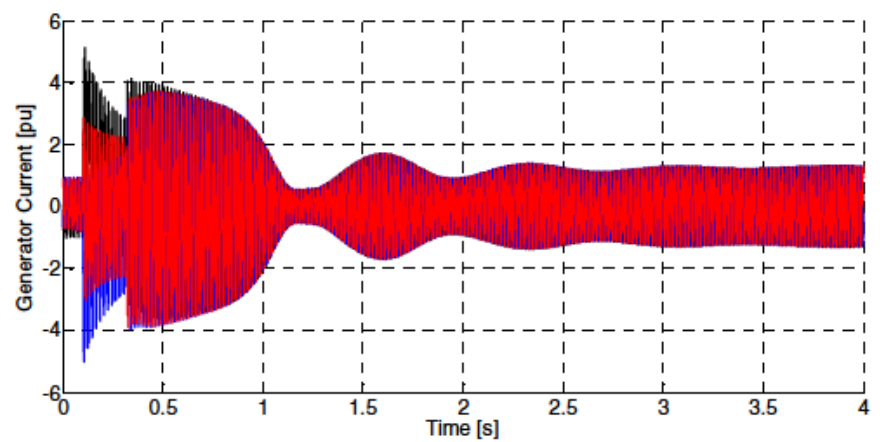

Fig. 12. Generator currents simulation results of a short-circuit in $220 \mathrm{kV}$ of $215 \mathrm{~ms}$ of a loss of excitation.

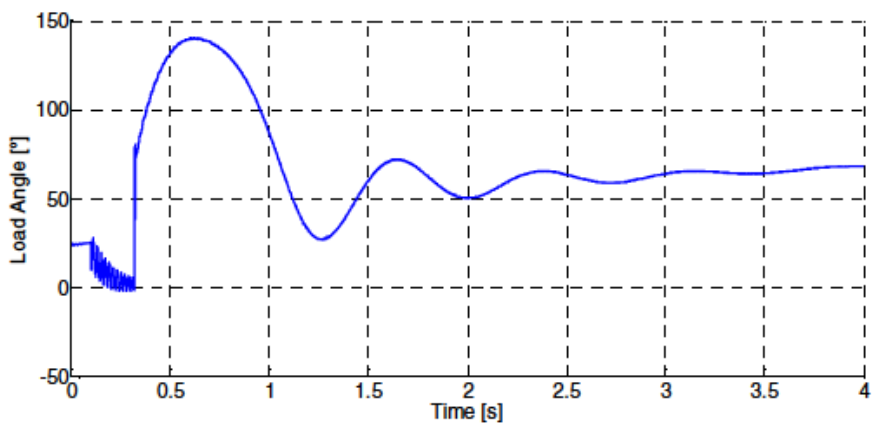

Fig. 13. Generator load angle simulation results of a short-circuit in $220 \mathrm{kV}$ of $215 \mathrm{~ms}$.

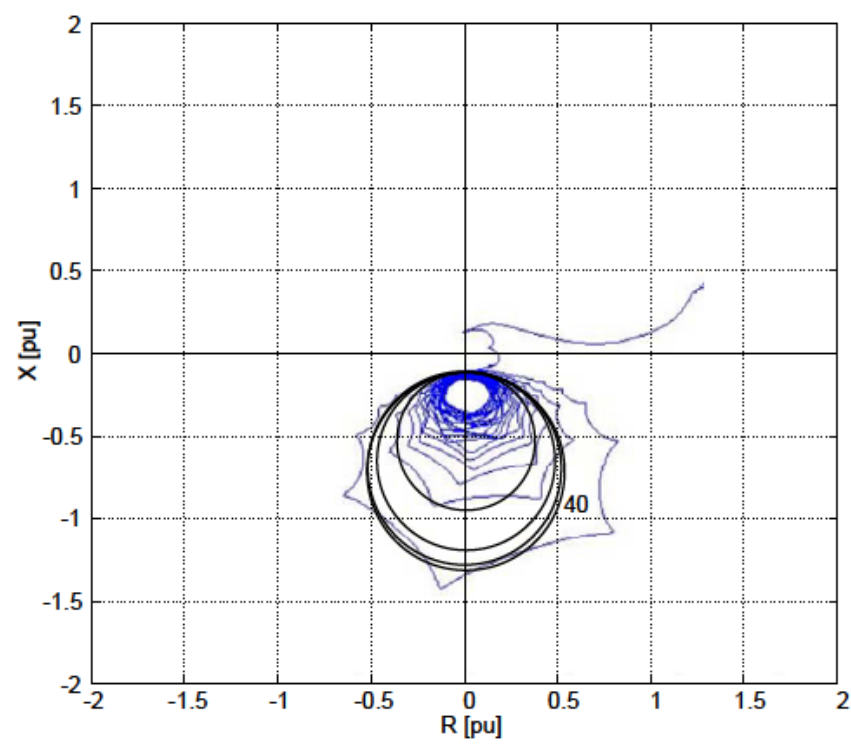

Fig. 14. Impedance at generator terminals simulation results of a short-circuit in $220 \mathrm{kV}$ of $220 \mathrm{~ms}$ for different loss of excitation protection settings.

In case of short-circuit with loss of stability the impedance at generator terminals could go into the loss of excitation 
protected area. In case of this failure the pole slip protection (ANSI 78) should trip, but not the loss of excitation protection. In this case the coordination should be done as the tripping time of the pole slip protection should be faster than the loss of excitation.

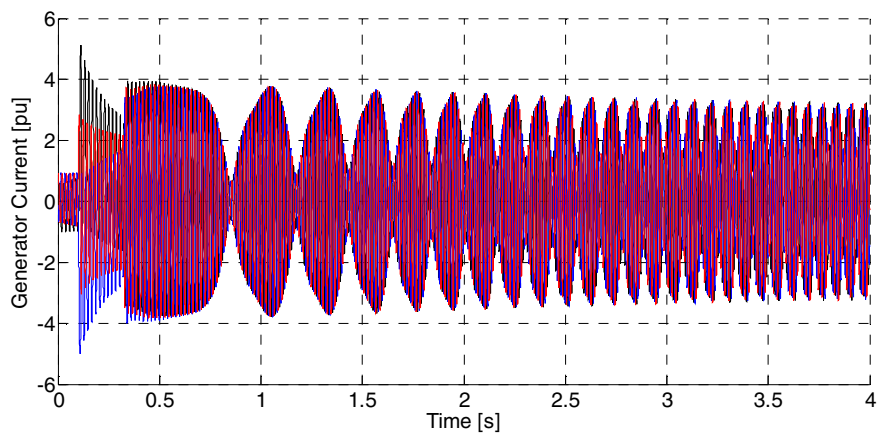

Fig. 15. Generator currents simulation results of a short-circuit in $220 \mathrm{kV}$ of $220 \mathrm{~ms}$ of a loss of excitation.

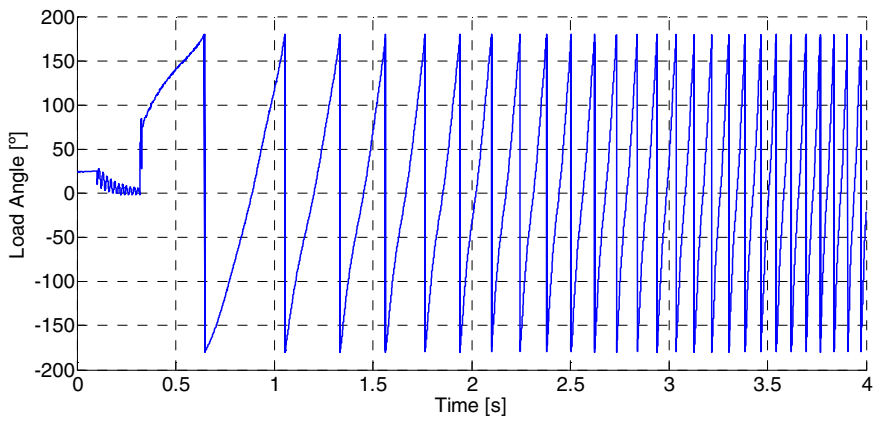

Fig. 16. Generator load angle simulation results of a short-circuit in $220 \mathrm{kV}$ of $220 \mathrm{~ms}$.

\section{CONCLUSIONS}

There are several recommendation setting of the loss of excitation protection, all of them based on generator reactances. A review has been presented in Table I.

According to the simulations all the proposed setting are suitable for a loss of excitation detection.

However some of the proposed settings could produce unwanted trips in case of reactive power absorption at low active load. This settings correspond to a $\mathrm{X}_{1}$ larger than $\mathrm{X}_{\mathrm{d}}$, so the protection area overlap with the generator curve capacity.

In case of an external faults as short-circuits in the power system, the loss of excitation protection should not trip. It is possible than the impedance at generator terminals go into the loss of excitation protected area. In this case the coordination with other protections, as pole slip, or minimum impedance protections should be done by different tripping time settings. This should be study by the use of computer power system simulators.

\section{REFERENCES}

[1] IEEE Guide for AC Generator Protection, IEEE Standard C37.102, 2006.

[2] ALSTOM, Network Protection \& Automation Guide, 2011

[3] M. Abedini; M. Sanaye-Pasand; M. Davarpanah, "An Analytical Approach to Detect Generator Loss of Excitation Based on Internal Voltage Calculation," in IEEE Transactions on Power Delivery, vol.PP, no. 99 , pp.1-1

[4] A. P. Morais, A. S. Bretas, S. Meyn and G. Cardoso, "Adaptive Mho relay for synchronous generator loss-of-excitation protection: a capability curve limit-based approach," in IET Generation, Transmission \& Distribution, vol. 10, no. 14, pp. 3449-3457, 1142016.

[5] B. Mahamedi, J. G. Zhu and S. M. Hashemi, "A Setting-Free Approach to Detecting Loss of Excitation in Synchronous Generators," in IEEE Transactions on Power Delivery, vol. 31, no. 5, pp. 2270-2278, Oct. 2016.

[6] H. Yaghobi, "Fast discrimination of stable power swing with synchronous generator loss of excitation," in IET Generation, Transmission \& Distribution, vol. 10, no. 7, pp. 1682-1690, 552016.

[7] B. Li, Z. Duan, X. Wang and J. Wu, "Loss-of-excitation analysis and protection for pumped-storage machines during starting," in IET Renewable Power Generation, vol. 10, no. 1, pp. 71-78, 12016.

[8] A. L. M. Coelho, C. E. B. Carrer, C. A. V. Guerrero and P. M. Silveira, "Loss-of-Excitation Protection and Underexcitation Controls Correlation for Synchronous Generators in a Real-Time Digital Simulator," in IEEE Transactions on Industry Applications, vol. 51, no. 5, pp. 3579-3590, Sept.-Oct. 2015.

[9] C. R. Mason, "A New Loss-of-Excitation Relay for Synchronous Generators," in Transactions of the American Institute of Electrical Engineers, vol. 68, no. 2, pp. 1240-1245, July 1949.

[10] Y. N. Gazen, A. B. Zarnott, A. P. de Morais, G. Cardoso and A. de Lima Oliveira, "New setting of loss of excitation protection in P-Q plan in order to maximize the operation area of the capacity curve of the synchronous machine," 2014 49th International Universities Power Engineering Conference (UPEC), Cluj-Napoca, 2014, pp. 1-6.

[11] J. Berdy, "Loss of excitation protection for modern synchronous generators," in IEEE Transactions on Power Apparatus and Systems, vol. 94, no. 5, pp. 1457-1463, Sept. 1975. 